\title{
Acute minocycline administration reduces brain injury and improves long-term functional outcomes after delayed hypoxemia following traumatic brain injury
}

\author{
Marta Celorrio, Kirill Shumilov, Camryn Payne, Sangeetha Vadivelu and Stuart H. Friess * (1)
}

\begin{abstract}
Clinical trials of therapeutics for traumatic brain injury (TBI) demonstrating preclinical efficacy for TBI have failed to replicate these results in humans, in part due to the absence of clinically feasible therapeutic windows for administration. Minocycline, an inhibitor of microglial activation, has been shown to be neuroprotective when administered early after experimental TBI but detrimental when administered chronically to human TBI survivors. Rather than focusing on the rescue of primary injury with early administration of therapeutics which may not be clinically feasible, we hypothesized that minocycline administered at a clinically feasible time point ( $24 \mathrm{~h}$ after injury) would be neuroprotective in a model of TBI plus delayed hypoxemia. We first explored several different regimens of minocycline dosing with the initial dose $24 \mathrm{~h}$ after injury and $2 \mathrm{~h}$ prior to hypoxemia, utilizing short-term neuropathology to select the most promising candidate. We found that a short course of minocycline reduced acute microglial activation, monocyte infiltration and hippocampal neuronal loss at 1 week post injury. We then conducted a preclinical trial to assess the long-term efficacy of a short course of minocycline finding reductions in hippocampal neurodegeneration and synapse loss, preservation of white matter myelination, and improvements in fear memory performance at 6 months after injury. Timing in relation to injury and duration of minocycline treatment and its impact on neuroinflammatory response may be responsible for extensive neuroprotection observed in our studies.
\end{abstract}

Keywords: Traumatic brain injury, Hypoxemia, Minocycline, Neuroprotection, Secondary injury, Pre-clinical trial

\section{Introduction}

Approximately 1.7 million people experience traumatic brain injury (TBI) each year and over 5 million face TBI-related disabilities [34]. Optimization of physiologic parameters and minimization of secondary insults such as hypotension, hypoxia, intracranial hypertension, and excitotoxicity are the primary goals of care

\footnotetext{
*Correspondence: friess@wustl.edu

Division of Critical Care Medicine, Department of Pediatrics, Washington University in St. Louis School of Medicine, 660 South Euclid Avenue, St. Louis, MO 63110, USA

Further information and requests for resources and reagents should be directed to and will be fulfilled by the Lead Contact, Stuart Friess.
}

after moderate and severe TBI $[6,26]$. Neuroprotective agents in experimental TBI have shown promise when administered before or very early after injury $[16,30,48]$. However, clinical trials of therapeutics demonstrating preclinical efficacy for TBI have failed to replicate these results in humans, in part due to the absence of clinically feasible therapeutic windows for administration of neuroprotective agents $[10,15,25,38,44,54]$.

Minocycline is a broad-spectrum tetracycline antibiotic, which has been studied as a neuroprotective agent in TBI $[32,43,46]$. Although minocycline is proposed to have pleiotropic effects on the brain, the main mechanism of action for neuroprotection is thought to original author(s) and the source, provide a link to the Creative Commons licence, and indicate if changes were made. The images or other third party material in this article are included in the article's Creative Commons licence, unless indicated otherwise in a credit line to the material. If material is not included in the article's Creative Commons licence and your intended use is not permitted by statutory regulation or exceeds the permitted use, you will need to obtain permission directly from the copyright holder. To view a copy of this licence, visit http://creativecommons.org/licenses/by/4.0/. The Creative Commons Public Domain Dedication waiver (http://creativeco mmons.org/publicdomain/zero/1.0/) applies to the data made available in this article, unless otherwise stated in a credit line to the data. 
be suppression of microglial activation after TBI [43]. Preclinical investigations on the efficacy of minocycline have utilized short temporal windows of administration (within one hour) after injury reducing translatability of these findings to the clinical setting [20, 35, 42]. A recent clinical trial of minocycline for chronic TBI demonstrated a reduction in chronic microglial activation but an exacerbation of neuronal degeneration in patients receiving minocycline for 12 weeks highlighting that neuroprotective benefits of minocycline may be dependent on timing of administration [39]. Furthermore, recent evidence suggests that timing and duration of microglial modulation in experimental TBI may impact injury severity and recovery $[23,52]$.

We have developed a mouse model of TBI with delayed secondary hypoxemia to incorporate a common secondary insult encountered by TBI patients in the intensive care setting [31]. We have previously demonstrated that delayed normocarbic hypoxemia $24 \mathrm{~h}$ after experimental TBI exacerbated injury and behavioral deficits up to 6 months after injury [14, 31]. Rather than focusing on the rescue of primary injury with early administration of therapeutics which may not be clinically feasible, we hypothesized that minocycline administered at a clinically feasible time point ( $24 \mathrm{~h}$ after injury) would be neuroprotective in a model of TBI plus delayed hypoxemia. Unlike the treatment of primary TBI in the field, TBI patients in the intensive care setting provide an opportunity for rapid administration of therapeutics with narrow temporal windows of efficacy.

In this preclinical trial, we first explored several different regimens of minocycline dosing with the initial dose $24 \mathrm{~h}$ after injury and $2 \mathrm{~h}$ prior to hypoxemia, utilizing short-term neuropathology to select the most promising candidate. We then conducted a preclinical trial to assess the long-term efficacy of a short course of minocycline finding reductions in hippocampal neurodegeneration and synapse loss, preservation of white matter myelination, and improvements in fear memory performance at a clinically relevant time point (6 months after injury).

\section{Material and methods}

\section{Traumatic brain injury and delayed hypoxemia}

All procedures were approved by the Washington University Animal Studies Committee and are consistent with the National Institutes of Health guidelines for the care and use of animals. Animals were housed 5/cage and had free access to water and food with 12-h light/ dark cycle. C57BL/6 J 8-week old male mice (Jackson Laboratory, Bar Harbor, ME) were used in the initial dose response study. For subsequent studies with the selected dose, C57BL/6 J 8-week old male and female mice (Jackson Laboratory, Bar Harbor, ME) were used. Mice were anesthetized with $5 \%$ isoflurane at induction, followed by maintenance at $2 \%$ isoflurane for the duration of the procedure. Buprenorphine sustained release $(0.5 \mathrm{mg} / \mathrm{kg}$ subcutaneously, Zoopharm, Windsor, $\mathrm{CO}$ ) was administered prior to scalp incision. The head was shaved and ear bars were used to stabilize the head within the stereotaxic frame (MyNeurolab, St. Louis, MO). Then, a single $5-\mathrm{mm}$ craniectomy was performed by an electric drill on the left lateral side of the skull centered $2.7 \mathrm{~mm}$ lateral from the midline and $3 \mathrm{~mm}$ anterior to lambda. For flow cytometry experiments and long-term behavioral studies, animals were randomized to sham or injury after craniectomy using a computer-generated numbers randomization. For animals undergoing controlled cortical impact (CCI), the 3-mm electromagnetic impactor tip was then aligned with the craniectomy site at $1.2 \mathrm{~mm}$ left of midline, $1.5 \mathrm{~mm}$ anterior to the lambda suture. The impact was then delivered at $2 \mathrm{~mm}$ depth (velocity $5 \mathrm{~m} / \mathrm{s}$, dwell time $100 \mathrm{~ms}$ ) to produce a moderate level of injury. All animals then received a loose fitting $7 \mathrm{~mm}$ plastic cap secured over the craniectomy with Vetbond (3 M, St. Paul, MN). The skin was closed with interrupted sutures and treated with antibiotic ointment before removing the mouse from anesthesia and allowing recovery on a warming pad. One day after surgery, animals who had undergone $\mathrm{CCI}$ experienced hypoxemia $\left(8 \% \mathrm{O}_{2}, 4 \% \mathrm{CO}_{2}\right)$ for $60 \mathrm{~min}$ in a Coy labs hypoxia chamber (Coy Laboratory, Grass Lake, MI). A mixture of $\mathrm{N}_{2}, \mathrm{O}_{2}$, and $\mathrm{CO}_{2}$ was utilized to maintain normocarbic hypoxemia [31]. Sham animals did not experience hypoxemia and were placed in cages directly next to the chamber while injured animals were in hypoxia chamber. After hypoxemia, sham and CCI littermates were returned to their original cages. All animals were subjected to identical transport and handling regardless of group assignment throughout all experiments.

\section{Minocycline administration}

Previous preclinical studies have reported efficacy of minocycline for brain injury with dosing ranging from 22.5 to $90 \mathrm{mg} / \mathrm{kg} /$ dose $[19,24,32,49]$. We designed a two-step funnel design for four different dosing regimens of minocycline with an initial evaluation of efficacy using short-term neuropathology followed by selecting the most efficacious dosing for long-term behavioral outcome studies. On post injury day $1,2 \mathrm{~h}$ prior to hypoxemia, animals were randomized to receive minocycline (Sigma, St Louis, MO) $45 \mathrm{mg} / \mathrm{kg}, 90 \mathrm{mg} / \mathrm{kg}, 180 \mathrm{mg} / \mathrm{kg}$ or saline vehicle via intraperitoneal (i.p.) injection. Minocycline was dissolved in sterile saline at a concentration of $12.5 \mathrm{mg} / \mathrm{mL}$ in a water bath heated to $80{ }^{\circ} \mathrm{C}$ and then sterile filtered through a $0.22 \mu \mathrm{m}$ filter. Control animals received an equal volume of sterile saline. First injections 
were administered to injured and sham animals $22-25 \mathrm{~h}$ after surgery. For 3 of the minocycline groups, the respective doses were repeated on post injury days 2 and 3 . For the fourth minocycline group, after receiving an initial dose of minocycline $90 \mathrm{mg} / \mathrm{kg} 2 \mathrm{~h}$ prior to hypoxemia, mice received an additional 5 doses of minocycline $45 \mathrm{mg} / \mathrm{kg}$ every $12 \mathrm{~h}$. Because of the variation in number and volume of i.p. injections, each minocycline group had their own saline vehicle-control group for short-term neuropathological analysis.

\section{Immunohistochemistry}

Mice were euthanized under isoflurane anesthesia by transcardial perfusion with cold $0.3 \%$ heparin in PBS followed by $4 \%$ paraformaldehyde (PFA) (Sigma, St. Louis, $\mathrm{MO}$ ). Whole brains were removed and post-fixed in $4 \%$ for $24 \mathrm{~h}$, followed by equilibration in $30 \%$ sucrose for at least $48 \mathrm{~h}$ before sectioning. Serial $50-\mu \mathrm{m}$ thick coronal slices were cut on a freezing microtome starting with the appearance of a complete corpus callosum (CC) and caudally to bregma $-3.08 \mathrm{~mm}$. Immunohistochemical staining was performed on free-floating sections washed in Tris-buffered saline (TBS) between applications of primary and secondary antibodies. Endogenous peroxidase was blocked by incubating the tissue in TBS plus $0.3 \%$ hydrogen peroxide for $10 \mathrm{~min}$. Normal goat serum (3\%) in TBS with $0.25 \%$ Triton X (TBS-X) was used to block nonspecific staining for all antibodies. Slices were then incubated at $4{ }^{\circ} \mathrm{C}$ overnight with the primary antibodies (Table 1). For colorimetric immunohistochemistry, antibody binding was detected by incubating sections with biotinylated secondary antibodies (Table 1) in TBS-X Colorization was achieved using the VECTASTAIN Elite avidin-biotin complex (ABC)-HRP kit solution (Vector Laboratories, Burlingame, $\mathrm{CA}$ ) followed by the application of $3-3^{\prime}$-diaminobenzidine $\left(3-3^{\prime}-D A B\right.$, Sigma-Aldrich). Sections were mounted on glass slides in TBS-X, dried and dehydrated in 50\%, 70\%, 95\% and twice with $100 \%$ ethanol followed by Xylene (SigmaAldrich) before coverslipping with Dibutylphthalate Polystyrene Xylene (DPX, Sigma-Aldrich). For fluorescent immunohistochemistry, antibody binding was detected by incubating sections with Alexa fluorescence secondary antibody (Table 1) for $2 \mathrm{~h}$. Sections were mounted on glass slides in TBS-X, dried, and coverslipped with mounting medium for fluorescence with DAPI.

\section{Quantification of immunohistochemistry}

Stereological analysis was performed using StereoInvestigator software (MBF Bioscience, Williston, Vermont). Assessments were made by an investigator blinded to group assignment. The optical fractionator function was used to quantify target markers per cubic millimeter of tissue. A grid size of $125 \times 125 \mu \mathrm{m}$ and a counting frame

Table 1 Overview of the primary antibodies used in the present study

\begin{tabular}{|c|c|c|c|c|c|c|c|}
\hline \multirow[t]{3}{*}{ Antibody } & \multirow[t]{3}{*}{ Fluorophore } & \multirow[t]{3}{*}{ Clone } & \multirow[t]{3}{*}{ Species } & \multicolumn{2}{|c|}{ Dilution } & \multirow[t]{3}{*}{ Source } & \multirow[t]{3}{*}{ Product number } \\
\hline & & & & Tissue & In vitro & & \\
\hline & & & & IHQ & FC & & \\
\hline CD45 & BV425 & 30-F11 & Rat monoclonal & & $1: 200$ & BioLegend & 103134 \\
\hline $\mathrm{CD} 3 \boldsymbol{\varepsilon}$ & AF700 & $500-A 2$ & Armenian Hamster monoclonal & & $1: 100$ & BioLegend & 100320 \\
\hline CD11b & BV510 & $\mathrm{M} 1 / 70$ & Rat monoclonal & & $1: 500$ & BioLegend & 101263 \\
\hline MHC-II & PerCP-710 & AF6-120.1 & Mouse monoclonal & & $1: 200$ & eBioscience & $46-5320-80$ \\
\hline TLR4 & PE-Cy7 & SA15-21 & Rat monoclonal & & $1: 250$ & BioLegend & 145407 \\
\hline Ly6C & BV785 & HK1.4 & Rat monoclonal & & $1: 2000$ & BioLegend & 128041 \\
\hline Ly6G & AF700 & $1 \mathrm{~A} 8$ & Rat monoclonal & & $1: 100$ & BioLegend & 127622 \\
\hline NeuN & & A60 & Rabbit polyclonal & $1: 4000$ & & Millipore & MAB377 \\
\hline Ibal & & NCNP24 & Rabbit polyclonal & $1: 1000$ & & Wako & 019-19741 \\
\hline CD68 & & Gp110 & Rabbit polyclonal & $1: 1000$ & & Invitrogen & PA5-32330 \\
\hline PDGFR-a & & & Goat polyclonal & $1: 250$ & & R \& D systems & AF1062 \\
\hline PSD-95 & & & Rabbit polyclonal & $1: 200$ & & Invitrogen & $51-6900$ \\
\hline Synapsin & & & GuineaPig & $1: 1000$ & & Synaptic systems & 106004 \\
\hline Secondary antibody & AF488 & & Goat anti-rabbit & $1: 500$ & & Thermo Fisher & A-32731 \\
\hline Secondary antibody & AF568 & & Goat anti-guinea pig & $1: 500$ & & Thermo Fisher & A-11073 \\
\hline Secondary antibody & AF568 & & Donkey anti-goat & $1: 500$ & & Thermo Fisher & A-11055 \\
\hline Secondary antibody & AF488 & & Donkey anti-rabbit & $1: 500$ & & Thermo Fisher & A-21206 \\
\hline Secondary antibody & & & Biotinylated goat anti-rabbit & $1: 1000$ & & Vector Laboratories & BA-1000-1.5 \\
\hline
\end{tabular}


of $25 \times 25 \mu \mathrm{m}$ was used for stereological quantification of $\mathrm{NeuN}+$ cells in the pyramidal layer of Cornu Ammonis (CA) 3 region of the ipsilateral hippocampus. For stereological quantification of Iba1+ or CD68+ cells in the CA3 region of the ipsilateral hippocampus, the optical fractionator function was again used, with a grid size of $180 \times 180 \mu \mathrm{m}$ and a counting frame of $80 \times 80 \mu \mathrm{m}$. For all stereological quantifications 4 slices spaced $300 \mu \mathrm{m}$ apart were analyzed. The volume of the region of interest was calculated using the Cavalieri estimator. Gunderson's coefficients of error were $<0.1$ for all stereological quantifications.

\section{Three-dimensional reconstruction of microglia and oligodendrocyte progenitor cells}

Microglia (Iba1) and oligodendrocyte progenitor cells (OPC, PDGFR- $\alpha$ ) morphology analysis was performed as previously described [17]. Fifty- $\mu \mathrm{m}$ sections were stained with Iba1 and PDGFR- $\alpha$ at $4{ }^{\circ} \mathrm{C}$ overnight (Table 1), followed by Alexa Fluor conjugated secondary antibody staining (Table 1 ) for $2 \mathrm{~h}$. Sections were mounted on glass slides in TBS-X, dried, and coverslipped with mounting medium for fluorescence with DAPI. Imaging was performed on a Zeiss LSM 880 confocal laser scanning microscope (Zeiss, White Plains, NY) using a $20 \times 0.8$ NA objective. Z-stacks were done with $1.00-\mu \mathrm{m}$ steps in $\mathrm{z}$ direction; $1024 \times 1024$ pixel resolution were recorded and analyzed using IMARIS software (Bitplane, Concord, MA). For microglia 3D reconstruction, a total of three hippocampal Iba1+cells from the CA3 region of the hippocampus from one slice were analyzed by an investigator blinded to group assignment. For OPC 3D reconstruction, a total of 9 PDGFR- $\alpha+$ cells from the hilus of the ipsilateral dentate gyrus (DG) from 3 slices were analyzed (three PDGFR- $\alpha+$ cells per slice) by an investigator blinded to group assignment.

\section{Fluorescence immunohistochemistry and quantification}

To perform quantitative analysis of OPC density in the DG region of the hippocampus, fluorescent images were obtained with a Zeiss Axio Imager Z2 with Apotome 2 with a $20 \times$ objective. The region of interest was the hilus of the DG. Quantification was performed on 3 coronal slices per mouse spaced $300 \mu \mathrm{m}$ apart.

\section{Cresyl violet-staining}

Cresyl violet staining was used for the detection of Nissl bodies in the cytoplasm of neurons on PFA sections in order to measure lesion and hippocampal volume. Twelve $50-\mu \mathrm{m}$ thick slices sampled at $300 \mu \mathrm{m}$ intervals starting with the appearance of the CC were utilized. After 3 washes in TBS, tissue was mounted on charged slides and dried overnight. The following day, slides were put in a cylinder glass holder and incubated in FD cresyl violet solution (FD Neurothecnologies, Inc, Colombia, $\mathrm{MD}$ ) for $10 \mathrm{~min}$. The remaining cresyl violet solution was rinsed away with water for $20 \mathrm{~min}$. Then, the slides were dried and dehydrated in 95\% ethanol (10 min), twice in $100 \%$ ethanol placed in xylene $(8 \mathrm{~min})$ before being coverslipped with DPX.

\section{Lesion volume analysis}

The extent of tissue loss in the ipsilateral hemisphere for each animal was quantified using images of cresyl violetstained slices acquired at $5 \times$ objective with a Zeiss Axio Scan Z1 Brightfield microscope (Zeiss, White Plains, NY). Tissue loss in the injured hemisphere was calculated as a percentage of the tissue volume in the contralateral hemisphere as described by others [47].

\section{Myelin Black Gold II staining}

Myelin Black Gold II (BGII, Histo-Chem, Jefferson, AR) staining was used for visualizing individual myelin fibers in the CC in order to assess white matter injury. After 3 washes in TBS, free floating slices were incubated for $12 \mathrm{~min}$ and $60{ }^{\circ} \mathrm{C}$ in pre-warmed BGII solution $(0.3 \%$ in $0.9 \% \mathrm{NaCl}$ ), followed by 2 washes in distilled water. Slices were fixed in pre-heated sodium thiosulfate $(1 \%$ in distilled water) at $60^{\circ} \mathrm{C}$ for $3 \mathrm{~min}$. Tissue was mounted on charged slides and dried overnight. The following day, slides were dehydrated using a serial of graded alcohols (50\%, 70\%, 95\% and twice with 100\%) and coverslipped with DPX. Slides were scanned at $10 \times$ objective with a Zeiss Axio Scan Z1 Brightfield microscope (Zeiss, White Plains, NY). Four slices spaced $300 \mu \mathrm{m}$ apart were analyzed with the most rostral slice being the first appearance of the dorsal hippocampus. Myelin percent area in the $\mathrm{CC}$ was quantified using ImageJ software. The CC region of interest was defined as the white matter area between the bilateral edges of the cingulum.

\section{Cell suspensions}

The blood and the ipsilateral cortex and hippocampus were taken 7 days after CCI or sham surgery. Mice were anesthetized with isoflurane, and blood samples were taken in EDTA tubes immediately before transcardial perfusion with ice-cold $0.1 \mathrm{M}$ heparinized-PBS. The brain regions of interest were dissected out on ice and digested at $37{ }^{\circ} \mathrm{C}$ for $15 \mathrm{~min}$ with collagenase D (400 units/mL, Roche) in Dulbecco's PBS (Lonza, Basel, Switzerland), each containing $50 \mu \mathrm{g} / \mathrm{mL}$ of DNase I (SigmaAldrich). The tissue was then mechanically dissociated with a glass Pasteur pipette, filtered through a $70-\mu \mathrm{m}$ nylon cell strainer, and centrifuged at $950 \mathrm{rpm}$ for $15 \mathrm{~min}$. A 25\% Percoll (Sigma-Aldrich) column was used to remove cell debris and myelin, followed by centrifugation 
at $1700 \mathrm{rpm}$ for $10 \mathrm{~min} .50 \mu \mathrm{l}$-blood sample was mixed with $1 \times$ Red Blood Lysis Buffer (Roche) and incubated in rotation for $15 \mathrm{~min}$ at room temperature (RT). Samples were then centrifuged at $3500 \mathrm{rpm}$ for $5 \mathrm{~min}$ at RT. The supernatant was discarded, and cells were washed and resuspended in $1 \mathrm{~mL}$ of cytometer buffer [0.5\% bovine serum albumin (Sigma-Aldrich), $5 \mathrm{mM}$ EDTA (Millipore, Burlington, MA) in PBS]. The cells were resuspended in $100 \mu \mathrm{l}$ of cytometer buffer and stained.

\section{Flow cytometry analysis}

Cells were incubated for $5 \mathrm{~min}$ at RT with Zombie NIR Dye (BioLegend, San Diego, CA, USA) to assess their viability. The Zombie NIR Dye was quenched, and cells were washed with cytometry buffer and blocked with FcR blocking reagent (1:50, Miltenyi Biotec, Bergisch Gladbach, Germany). Then, the samples were washed with cytometry buffer, stained with antibodies (Table 1) for 15 min at RT, and analyzed on a BD LSRFortessa flow cytometer (BD Biosciences, Franklin Lakes, NJ) using the Software v10.6.1 (BD Biosciences, Franklin Lakes, NJ). Microglial cells were defined as $\mathrm{CD} 45^{\text {low }} \mathrm{CD} 11 \mathrm{~b}^{+}$and $\mathrm{T}$ cells as $\mathrm{CD} 45^{\text {high }} \mathrm{CD} 11 \mathrm{~b}^{-} \mathrm{CD} 3^{+}$.

\section{Quantification of synaptic loci}

Quantification of synaptic loci was performed utilizing a semi-automated pipeline based on MATLAB (MathWorks, Portola Valley, CA) and Imaris 9.3.1 software (Bitplane, Concord, MA) as previously described [36]. Three confocal images were obtained on a LSM 880 microscope with AiryScan detector (Zeiss) from the ipsilateral molecular layer of the DG for each animal. Spots were detected for each channel using an $\mathrm{x}-\mathrm{y}$ size of $0.2 \mu \mathrm{m}$, a $\mathrm{z}$ size of $0.6 \mu \mathrm{m}$, and automated background subtraction. A $0.1-\mu \mathrm{m} x-y$ and $0.3-\mu \mathrm{m} z$ guard was applied to exclude spots intersecting the edge of the image volume. Synaptic loci were identified using previously developed MAT$L A B$ scripts to find the nearest neighbor based on the $x-y-z$ centroid of the top $20 \%$ brightest puncta. A cutoff of $260 \mathrm{~nm}$ pre-to-postsynaptic separation was used to quantify synaptic loci.

\section{Behavioral studies}

Animals underwent behavioral testing 6 months after sham surgery or CCI. A total of 39 male and 39 female mice underwent long-term behavioral testing divided into six same sex cohorts of 13-15 animals. In each cohort, animals were randomized to sham surgery, injured-mice treated with vehicle (CCI-vehicle), or injured-mice treated with minocycline (CCI-minocycline). On post-injury day 1 , injured animals were randomized to receive minocycline every $12 \mathrm{~h}$ (first dose $90 \mathrm{mg} / \mathrm{kg}$, followed by 5 doses of $45 \mathrm{mg} / \mathrm{kg}$ i.p.) or an equivalent volume of normal saline. All tests were conducted by an experimenter blinded to group assignment. Animals were handled by the experimenter on three consecutive days prior to the initiation of testing. The order of tests was as follows: novel object recognition (NOR), followed by fear conditioning with each test performed 2 weeks apart. Prior to each testing day, animals were acclimated to the testing room for $1 \mathrm{~h}$.

\section{Novel object recognition test}

NOR testing was performed as previously described $[8,27]$. Briefly, mice were handled by the experimenter twice a day 2 days before the beginning of the behavioral test. For the performance of the test, we used a square 4-chamber open field apparatus made of grey durable Plexiglas material $(40 \times 40 \times 30 \mathrm{~cm})$, and the luminosity of the room was adjusted with a luxmeter to obtain a light intensity of $20 \mathrm{~lx}$ in the center of the open field box. Animal activity was recorded automatically by a SMART video tracking software (Panlab Harvard apparatus, Barcelona, Spain) using an overhead USB-camera (Logitech, Newark, CA). On day 1 and 2 (habituation phase), mice were placed in the different arenas and allowed to explore the space for $5 \mathrm{~min}$ per day. On day 3 (familiarization session), mice were placed in the open field box in contact with two identical objects (towers of Lego bricks) at $5 \mathrm{~cm}$ from the walls for $10 \mathrm{~min}$. On day 4 (test day), mice were returned to the arenas where one of the objects was changed for a new object (small falcon tissue culture flask half-filled with mouse bedding). On day 1 and 2, time in center, time in periphery, and total distance were analyzed. We calculated the Discrimination Index (DI), allowing discrimination between the novel and familiar objects, i.e., the exploration time for novel object (TN) was divided by the total amount of time interacting with the novel and familiar objects $(\mathrm{TF}): \% \mathrm{DI}=(100 \times \mathrm{TN}) /$ $(\mathrm{TN}+\mathrm{TF})$. After every session, the open field box and objects were cleaned with $70 \%$ ethanol to minimize olfactory cues.

\section{Contextual and cued-fear conditioning}

Fear conditioning was performed 2 weeks after NOR as previously described $[8,9]$. A fear conditioning-system (Ugo Basile, Gemonio, Italy) consisting of a sound-attenuating box $(48.5 \times 38.5 \times 48.5 \mathrm{~cm})$ with ventilating fan, a light, overhead USB-camera (Logitech), and an electrical grid floor for inducing the foot-shocks was utilized. On day 1 (conditioning), mice were placed in context A and every $1.5 \mathrm{~min}$ they received 5 tone-shock pairings [30 s (s) tone with $0.5 \mathrm{~mA}$ and shock during the last $2 \mathrm{~s}$ ] and the freezing time in $30 \mathrm{~s}$ epochs was measured by a blinded observer. On day 2 (contextual test), mice were placed in context A for $10.5 \mathrm{~min}$ and freezing time was 
measured to assess contextual fear memory. On day 3 (cued test), mice were placed in a novel context B (checkered walls and white hard cover on the floor) to eliminate any confounding interactions of contextual fear for $10.5 \mathrm{~min}$ and subsequently given five $30 \mathrm{~s}$ tones without any shocks. On day 1 and 3, after the final tone-shock pairing, mice remained in the conditioning chamber for $30 \mathrm{~s}$ before being returned to their home cages. Freezing was defined as the absence of visible movement except that required for respiration. Percentage of total freezing time was calculated by dividing the amount of time-spent freezing by total time (630 s).

\section{Statistical analysis}

All data for each animal was entered and tracked utilizing a REDCap database to maintain data integrity [21]. For initial short-term studies, experiments were powered to detect a $30 \%$ difference between CCI-vehicle and CCI-minocycline treated animals. For long-term behavior studies, experiments were powered to detect a $33 \%$ improvement in performance of minocycline treated mice compared with vehicle controls. Data was assessed for normal distribution with Shapiro Wilk test. Student $t$ test or Mann Whitney U test were used for histological data and behavioral data when appropriate. For longterm behavior studies, experiments were conducted in cohorts of 10-15 animals. Before combining cohorts, two-way ANOVA was performed with cohort and group to confirm that cohort was not a significant factor or had a significant interaction with group. ANOVA and Kruskal-Wallis test were employed for normally and non-normally distributed data respectively. For sex dependent differences a two-way ANOVA was utilized. All analysis was performed with Statistica v13.3 (TIBCO software. Palo Alto, CA).

\section{Results}

Minocycline administration prior to secondary hypoxemia provides short-term neuroprotection

In our initial short-term studies, we selected 4 different dosing regimens of minocycline (Fig. 1ai, ii). Minocycline dosing of $180 \mathrm{mg} / \mathrm{kg}$ resulted in $80 \%$ mortality in the minocycline group by post-injury day 3 and no further investigation with this dose was performed. For our initial assessment of efficacy, we quantified neurons in the CA3 region of the hippocampus (Fig. 1b), a population known to be especially vulnerable to death post-CCI [11]. Minocycline dosing at $45 \mathrm{mg} / \mathrm{kg}$ once a day did not show evidence of neuronal protection (Fig. 1c). However, both dosing regimens with an initial dose of $90 \mathrm{mg} / \mathrm{kg}$ demonstrated similar reduction in neuronal loss (Fig. 1d, e). Based on the pharmacokinetics of minocycline in mouse models, we proceeded to utilize the twice a day dosing regimen (Fig. 1aii) for further study which minimizes peak plasma concentrations and more closely emulates human dosing of minocycline [41]. We did not observe any differences in lesion volume at 1 week post injury between any of the groups (Fig. 1f-h).

\section{Minocycline modulates microglial activation after delayed hypoxemia and TBI}

Minocycline when administered within $1 \mathrm{~h}$ after experimental TBI has been reported to suppress microglial activation [42]. To assess the impact of minocycline on the neuroinflammatory response after TBI and delayed hypoxemia, we performed flow cytometry on the ipsilateral cortex and hippocampus 7 days after injury (Fig. 2a). We observed a reduction in the total number of microglia $\left(\mathrm{CD} 45^{\text {low }} \mathrm{CD} 11 \mathrm{~b}^{+}\right.$, Fig. $\left.2 \mathrm{~b}\right)$ and the number of microglia expressing major histocompatibility complex II (MHCII) minocycline treated animals (Fig. 2c). Additionally, we found reduced brain infiltration of peripheral lymphocytes $\left(\mathrm{CD}^{+}\right.$Fig. 2e) and monocytes $\left(\right.$ Ly6 $\mathrm{C}^{+}$, Fig. 2f) in CCI-minocycline compared with CCI-vehicle. Flow cytometry of peripheral blood samples taken at time of sacrifice from the same mice revealed no differences in the peripheral blood immune cell populations arguing against systemic suppression of the peripheral immune response by minocycline (Additional file 1: Figure S1).

We next performed traditional stereological quantification of Iba1+cells in the CA3 region of the hippocampus. No differences in the number of Iba1 microglia was found between vehicle and minocycline treated mice at 1-week post injury (Fig. 3a, b). We also did not observe any sex dependent effects (data not shown). We further attempted to discern differences in activated microglia by utilizing the lysosomal marker CD68, but again stereological quantification did not reveal any significant differences between vehicle and minocycline treated injured mice in the CA3 region of the hippocampus (Fig. 3a, c). Minocycline has been reported to alter microglial morphology towards a more ameboid morphology in a perinatal mouse model [45]. To further characterize microglial changes with minocycline administration, we performed semi-automatic quantitative morphometric three-dimensional measurements of hippocampal microglia [17]. At 1 week post injury, hippocampal microglia from CCI-minocycline had decreased branch points (Fig. 3d), process length (Fig. 3e), terminal points (Fig. 3f), and number of segments (Fig. 3g) compared with CCI-vehicle. These data support minocycline's modulation of microglial activity and neuroinflammation as its mechanism for neuroprotection. 


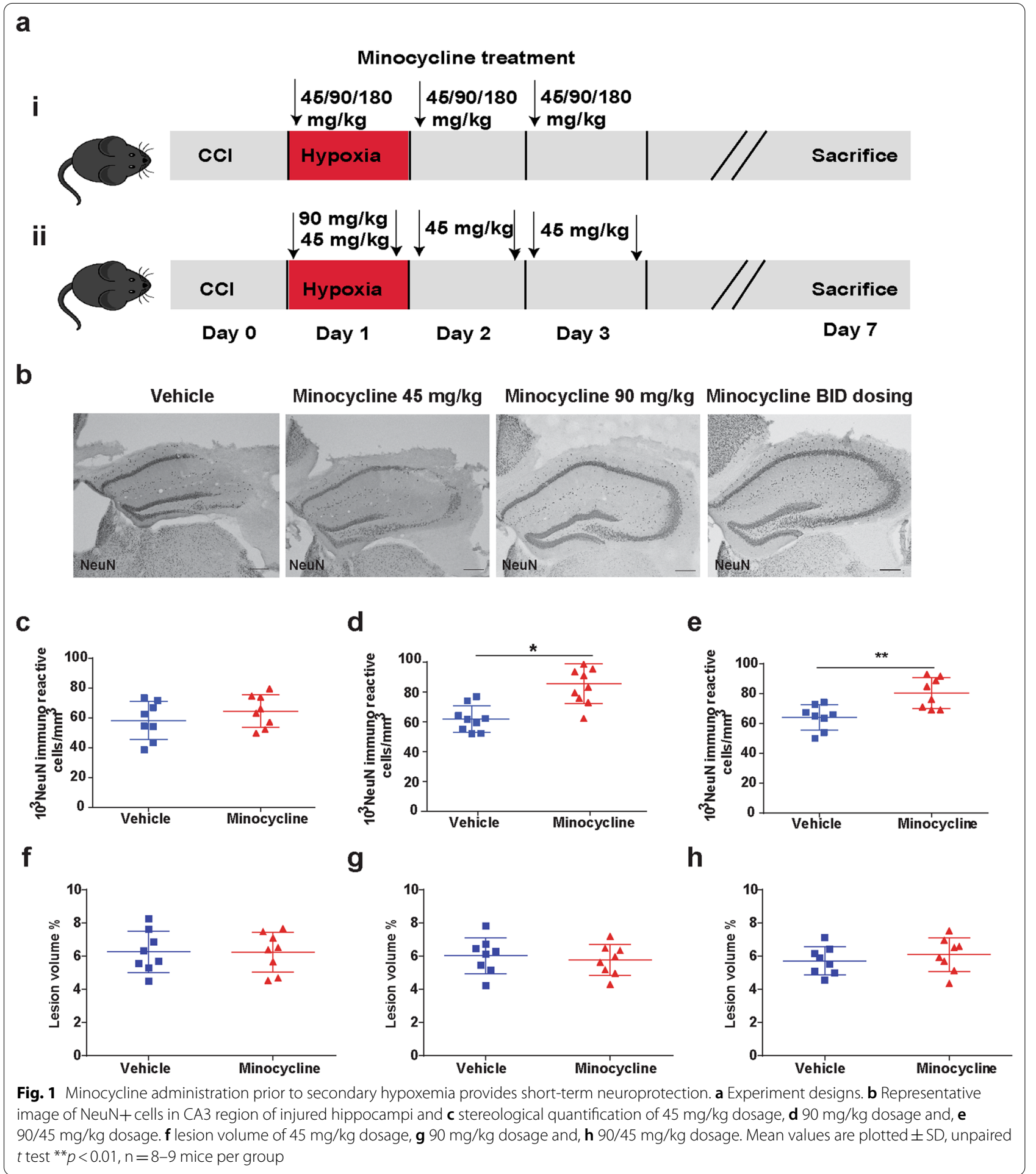

(See figure on next page.)

Fig. 2 Minocycline alters the immune system response in the hippocampus and cortex. a Gating strategy. b-g Quantification of absolute numbers

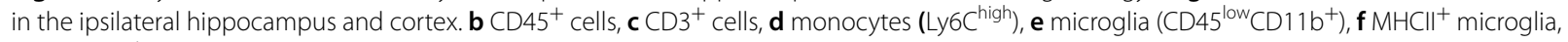
and $\mathbf{g}$ TLR4 $^{+}$microglia. Mean values are plotted \pm SD, One-way ANOVA followed by Tukey multiple comparison post hoc test were used to determine statistical differences; ${ }^{*} p<0.05 . n=8-10$ per group. Major histocompatibility complex II (MHCII). Toll-like receptor 4 (TLR4) 
a
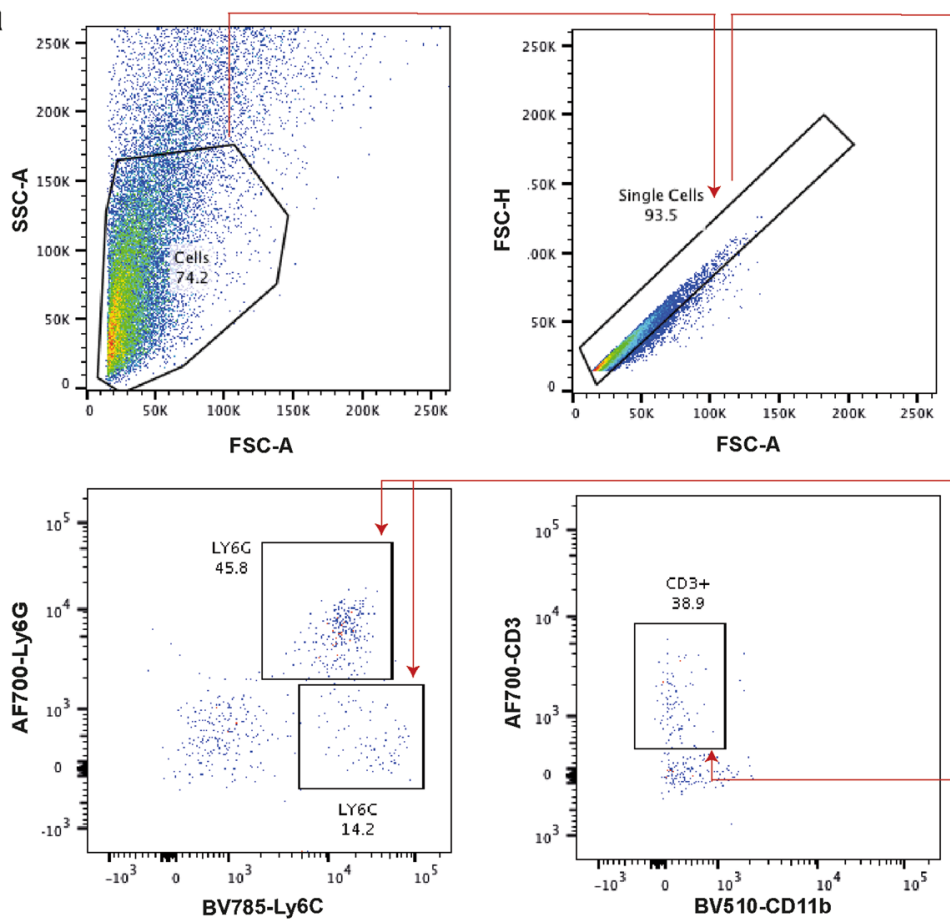

b

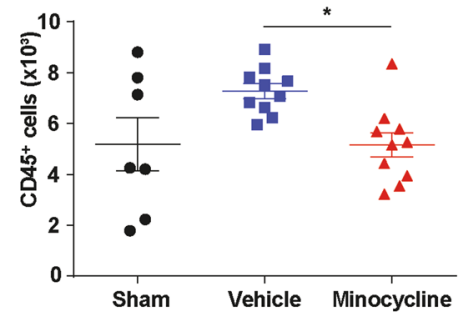

c
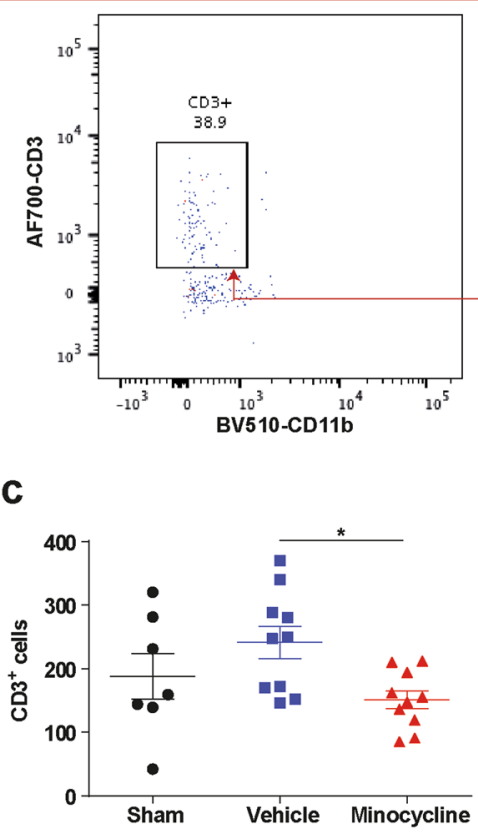

d

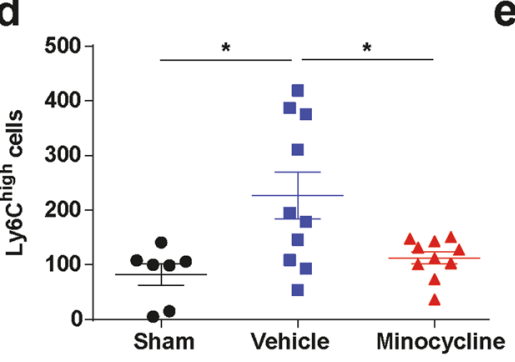

e

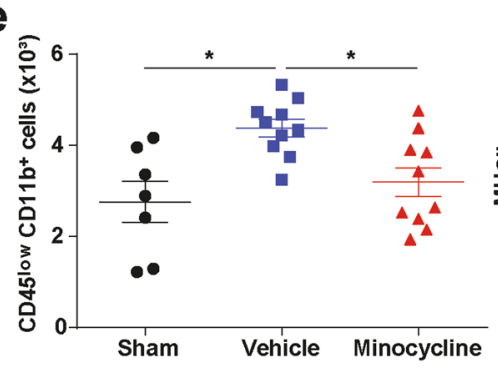

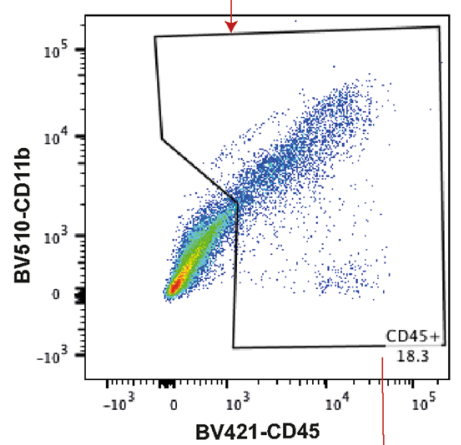

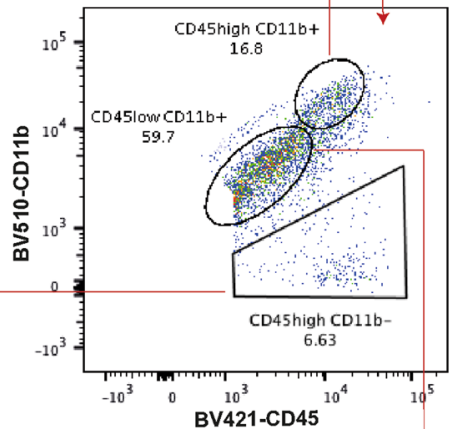

g

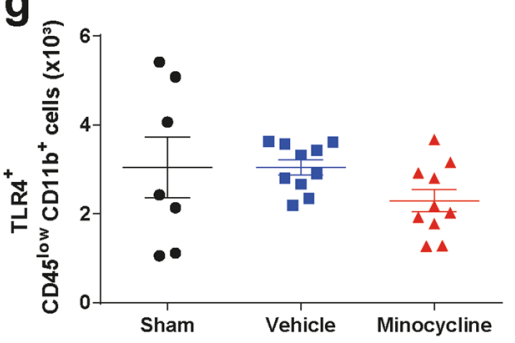

Fig. 2 (See legend on previous page.) 


\section{a}
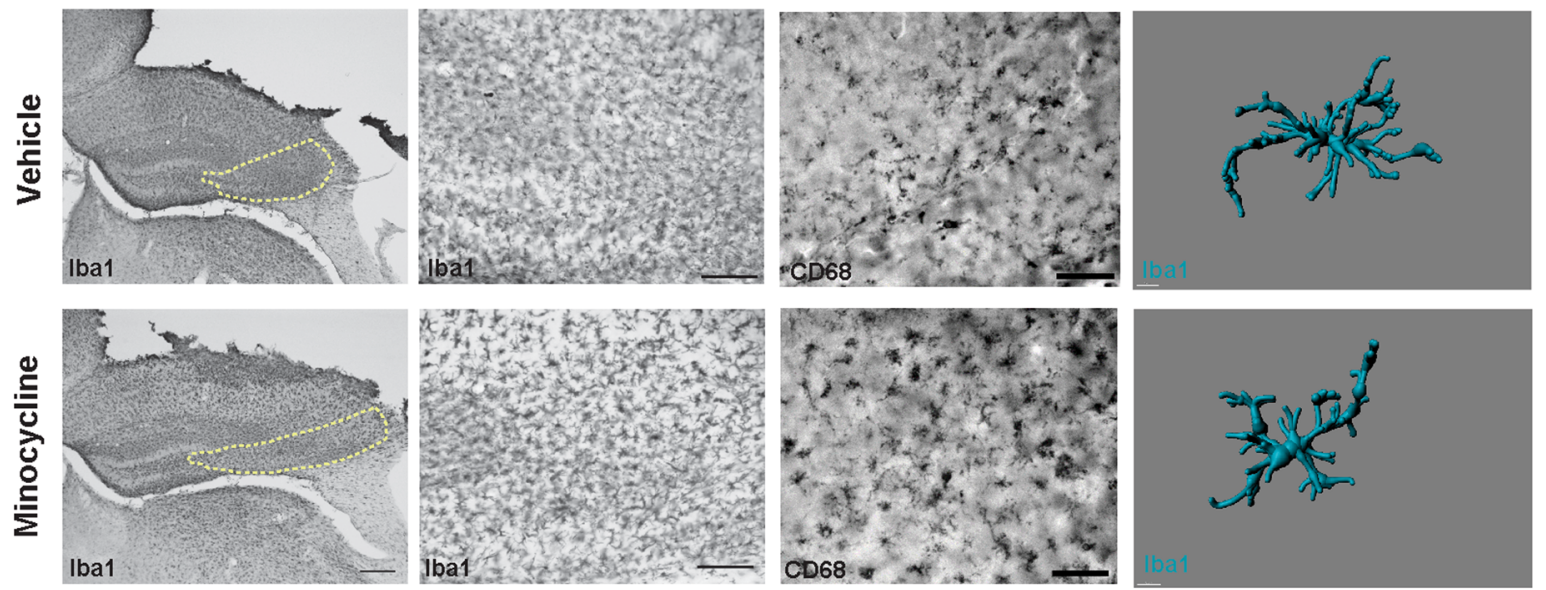

b

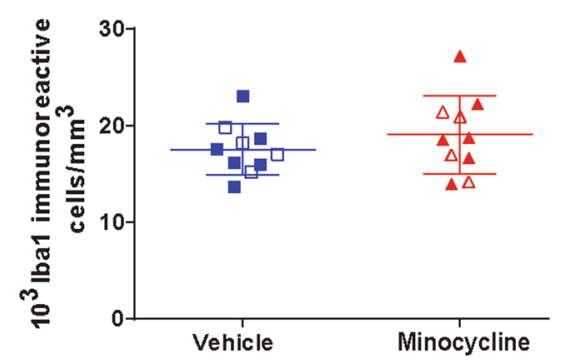

e

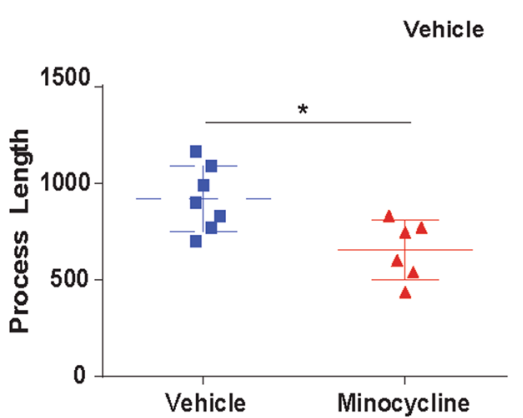

C

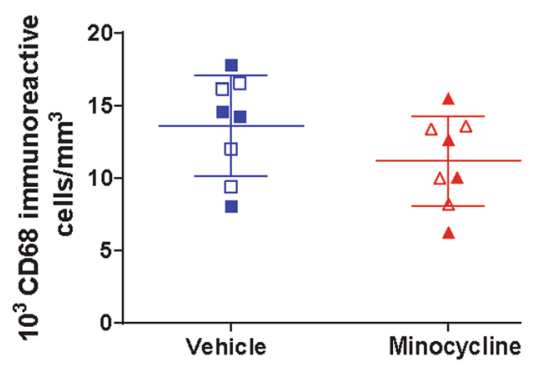

f

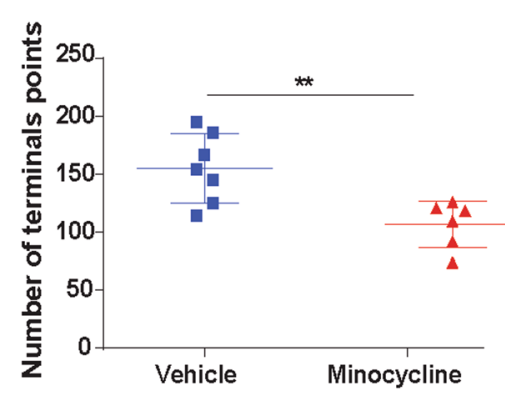

d

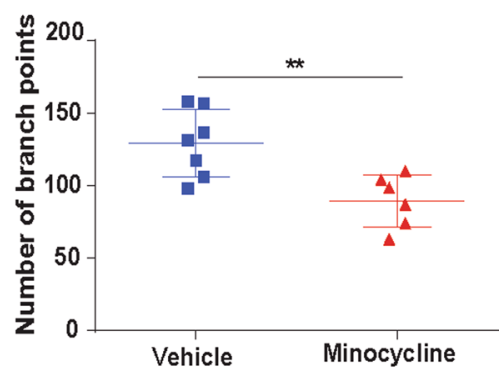

g

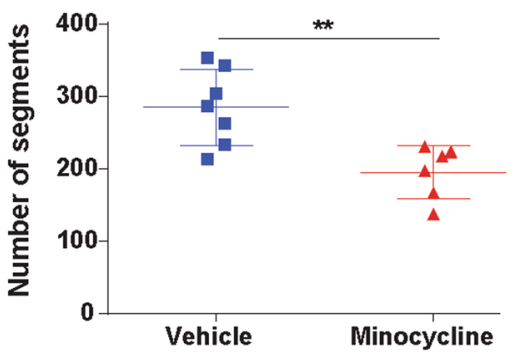

Fig. 3 Minocycline modulates microglia morphology. a Representative image of Iba1+ and CD68 + cells in CA3 region of injured hippocampi. Region of interest for stereological quantification represented by yellow dashed line. Representative three-dimensional reconstruction images of microglia cells. b Quantification of the Iba1+ cells density. c Quantification of the CD68+ cells density. Male mice represented by closed symbols, female mice represented by open symbols. Quantification of the microglia morphology of $\mathbf{d}$ number of branch points, e process length, $\mathbf{f}$ number of terminal points, and $\mathbf{g}$ number of segments. Mean values are plotted $\pm S D$, unpaired $t$ test ${ }^{* *} p<0.01, n=8$ mice per group

Minocycline does not improve acute post-TBI myelination but alters oligodendrocyte-progenitor cell morphology Previously we have reported, in our mice model of TBI with delayed hypoxemia, extensive white matter injury in the peri-contusional CC [31]. To assess the impact of minocycline administration on white matter injury after $\mathrm{CCI}$, we performed an analysis of BGII staining of the myelin fibers in the peri-contusional $\mathrm{CC}$ at 1 week after injury (Fig. 4a). Minocycline treatment had no effect on the percentage of myelinated area in the CC 1 week after injury (Fig. 4a, b).

Microglial activation after TBI contributes to $\mathrm{T}$ cell infiltration and impacting mature oligodendrocyte and OPC cell response [40]. We performed a quantitative 


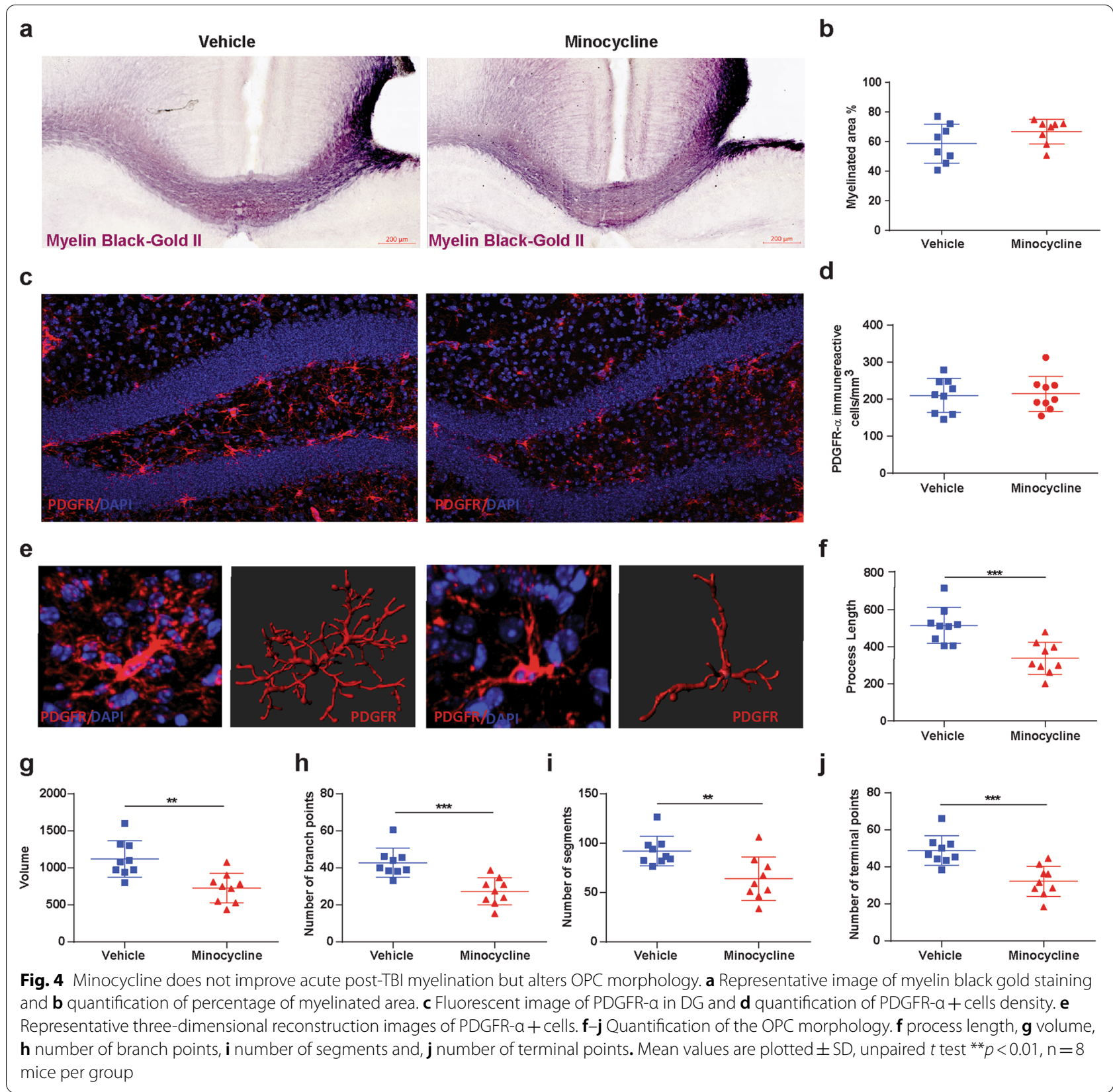

analysis of PDGFR- $\alpha+$ OPCs at 1-week post injury in the DG region of the ipsilateral hippocampus (Fig. 4c). Fluorescent immunohistochemical analysis of OPCs density revealed no significant difference between vehicle and minocycline treated animals (Fig. 4d). We then performed an analysis of OPC morphology in the DG at the same time point (Fig. 4e). Minocycline treatment resulted in significant decreases in process length (Fig. 4f), volume (Fig. 4g), number of branch points (Fig. 4h), number of segments (Fig. 4i), and terminal points (Fig. 4j) compared with vehicle. Suggesting that modulation of microglial activation after injury influences oligodendrogenesis.

\section{Minocycline improves long-term contextual-fear memory performance}

We next performed a long-term preclinical trial of our selected minocycline dosing (initial $90 \mathrm{mg} / \mathrm{kg}$ followed by 5 doses of $45 \mathrm{mg} / \mathrm{kg}$ every $12 \mathrm{~h}$ ) (Fig. $5 \mathrm{a}$ ). 76 mice ( 38 male and 38 female) were randomized sham or CCI-vehicle or CCI-minocycline. Five mice (all female) did not 


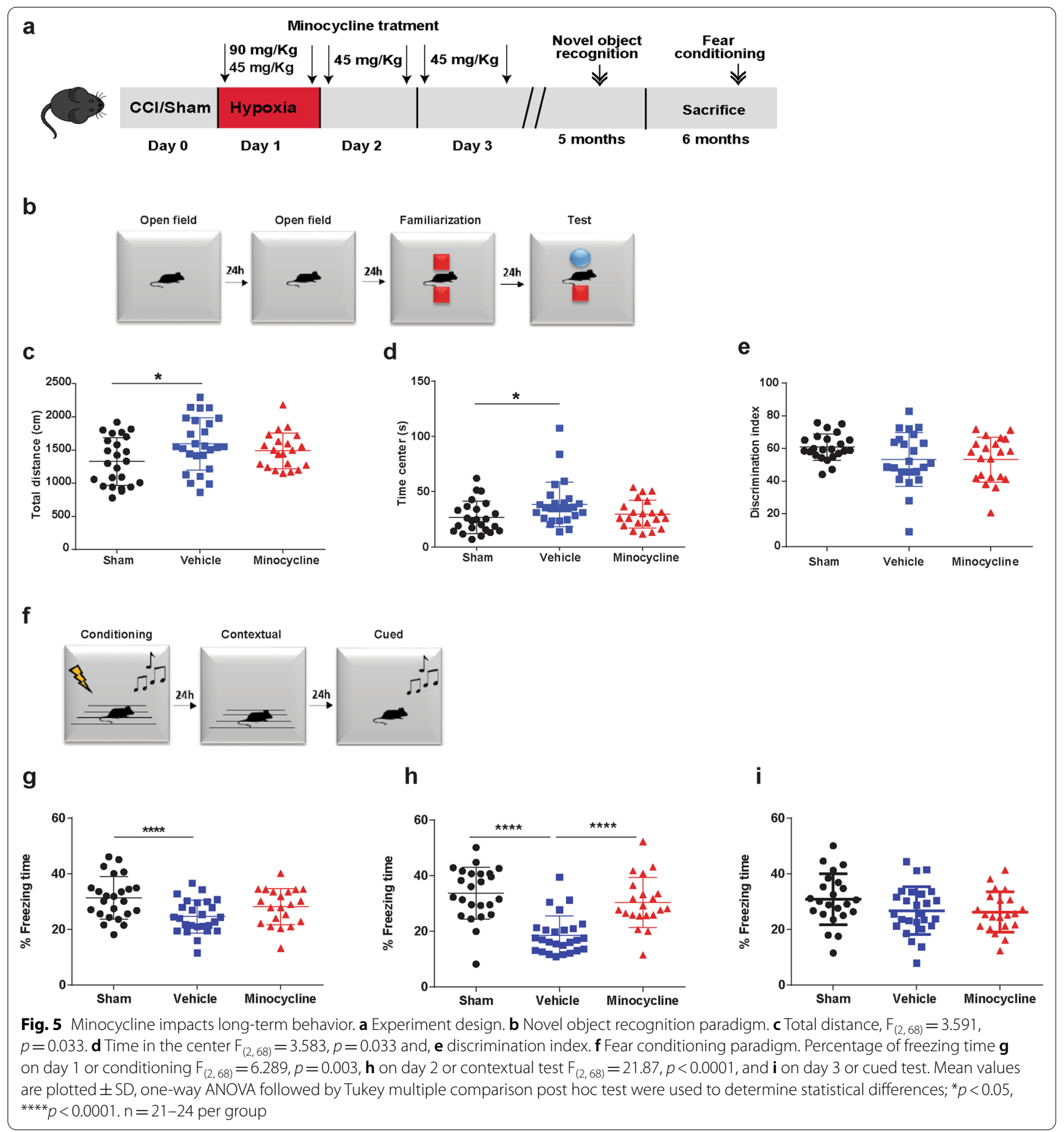

survive to behavior testing. One mouse randomized to minocycline was sacrificed $4 \mathrm{~h}$ after $\mathrm{CCI}$ due to an inability to return to general husbandry care. Four other mice died within seven days of surgery ( 2 sham and 2 minocycline mice). During open field testing (Fig. 5b), CCIvehicle were more active (Fig. $5 \mathrm{c}$ ) and spent more time in the center region (Fig. 5d) compared with sham. CCIminocycline were not statistically different than sham or
CCI-vehicle on post-hoc Tukey. Sham animals had better performance in NOR compared with injured animals but did not reach statistical significance $\mathrm{F}_{(2,70)}=3.87, p=0.09$ (Fig. 5e).

Changes in the fear memory response have been associated with disruptions in the hippocampal-amygdala circuit in chronic TBI linked with post-traumatic stress disorder [3, 33]. We employed a 3-day fear memory 
paradigm with conditioning on day 1 , contextual-fear response on day 2, and cued-fear response on day 3 (Fig. 5f). Sham animals had increased freezing compared with both injured groups during conditioning on day 1 (Fig. 5g). Interestingly, contextual-fear response which is hippocampal dependent was significantly different $\mathrm{F}_{(2,70)}=26.7, p<0.00001$ (Fig. 5h). CCI-minocycline had significantly higher freezing response compared with CCI-vehicle. Cued-fear response, amygdala-dependent task, was no different across the three groups (Fig. 5i). We did observe sex differences in contextual fear between sham animals but no sex dependent differences in either of the injury groups (Additional file 2: Figure S2). These data highlight that in a focal injury model, acute minocycline administration resulted in improved long-term hippocampal-dependent fear memory response.

\section{Acute minocycline administration reduces long-term neuronal and synapse loss}

We next performed stereological quantification of the CA3 region of the hippocampus from brains of the mice that had undergone behavioral testing (Fig. 6a, b). We found reduced neuronal loss in CCI-minocycline compared with CCI-vehicle (Fig. 6b). Iba1 immunohistochemistry

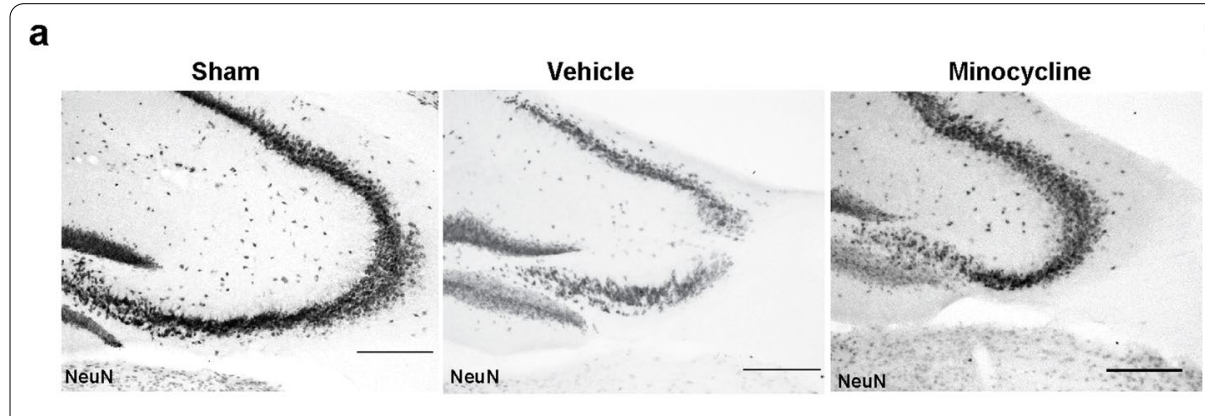

C
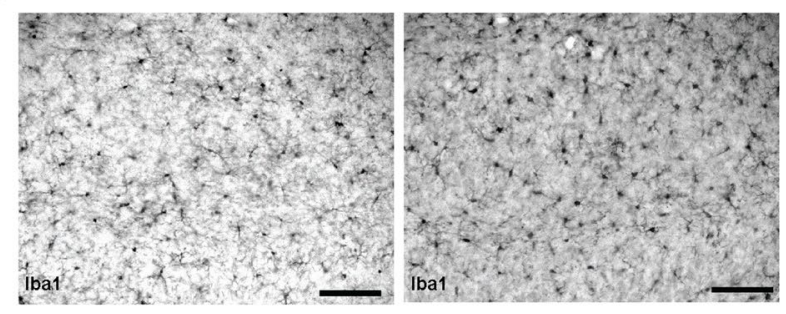

e

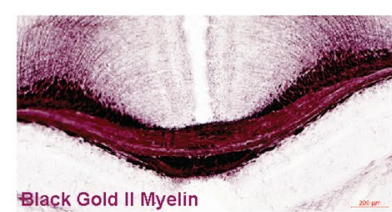

Black Gold II Myelin

g

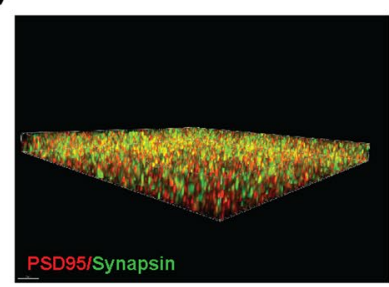

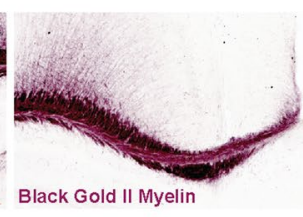

Black Gold II Myelin

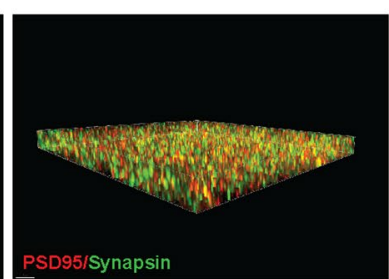

b

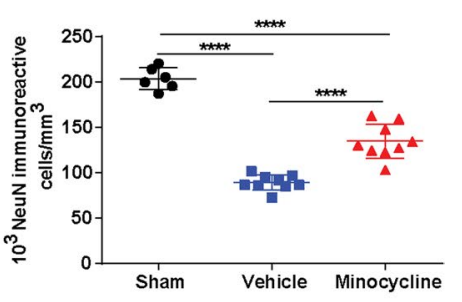

d
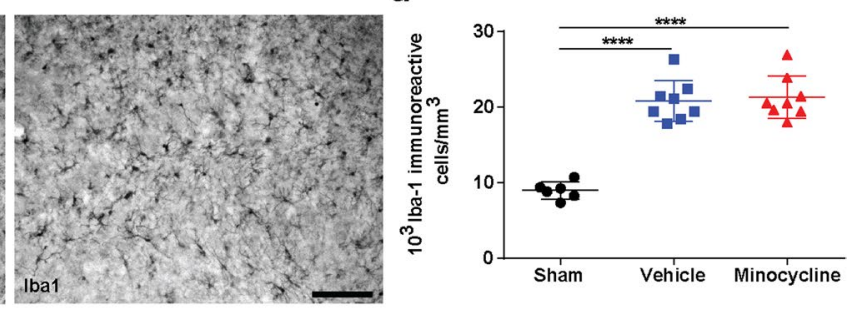

f
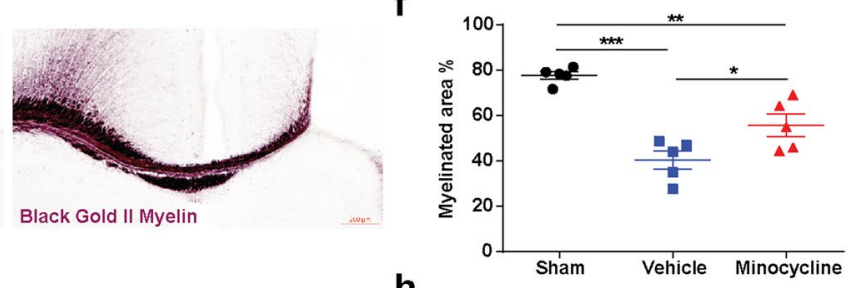

h
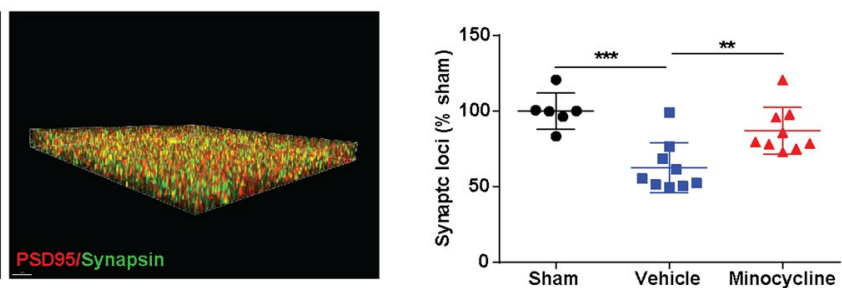

Fig. 6 Acute minocycline administration reduces long-term neuronal and synapse loss. a Representative image of NeuN+ cells in CA3 region of injured hippocampi and $\mathbf{b}$ stereological quantification $\left.\mathrm{F}_{2,21}\right)=117.7, p<0.0001$. c Representative image of Iba1 cells in CA3 region of injured hippocampi and $\mathbf{d}$ stereological quantification $\mathrm{F}(2,19)=52.5, p<0.0001$. e Representative image of myelin black gold staining and $\mathbf{f}$ quantification of percentage of myelinated area image of Iba1 cells in CA3 region of injured hippocampi and $\mathbf{d}$ stereological quantification $\mathrm{F}(2,12)=24.92, p<0.0001$. g Puncta detection of PSD95 (red) synapsin (green). h Quantification of synaptic loci (\% sham) $\mathrm{F}(2,21)=12.14$, $p<0.0003$. One-way ANOVA followed by Tukey multiple comparison post hoc test were used to determine statistical differences; ${ }^{*} p<0.05$. ${ }^{* *} p<0.01,{ }^{* * * *} p<0.001, \mathrm{n}=5-9$ per group 
revealed increased chronic microglial activation in both injured groups compared with sham but no minocycline effect was observed (Fig. 6c, d). In addition, we also found that CCI-minocycline had increased myelinated area 6 month after injury compared with CCI-vehicle (Fig. 6e, f). Microglia play an important role in synaptic plasticity and memory [12]. Based on our findings of improved hippocampal dependent contextual fear memory response, we utilized a recently developed super-resolution analysis workflow, synaptic evaluation and quantification by imaging nanostructure (SEQUIN) to evaluate long-term changes in synaptic density in the molecular layer of the DG (Fig. 6g, h). We chose the molecular layer of the DG based on previous reports of changes in synaptic density in this region associated with neurodegenerative diseases, as well as changes induced by chronic stress and physical activity [18, 22, 37]. We found reduced number of synaptic loci in vehicle-injured mice compared with injured mice who had received acute administration of minocycline (Fig. 6h) suggesting that acute minocycline administration improves long-term synaptic density associated with behavioral improvements.

\section{Discussion}

In summary, acute minocycline administration within a clinically feasible therapeutic window $24 \mathrm{~h}$ after experimental TBI and $2 \mathrm{~h}$ prior to systemic hypoxemia reduced microglial activation in the cortex and hippocampus and reduced acute neuronal loss in the CA3 region of the hippocampus. Furthermore, acute minocycline administration after injury improved fear memory response 6 months after injury and was associated with reduced hippocampal neuronal loss, reduced white matter myelin loss, and improved hippocampal synaptic density. Our results support the hypothesis that acute short-term administration of minocycline in a model of TBI with delayed systemic hypoxemia has a neuroprotective effect via reduced microglial activation.

Previous pre-clinical studies of minocycline in TBI have shown conflicting results on its neuroprotective efficacy $[19,35,46]$. These differences can be attributed to different injury models, variation in brain regions evaluated for changes in neuropathology, and timing/ dosing of minocycline administration. To overcome some of these challenges we chose to first evaluate the short-term neuroprotective efficacy of various dosing regimens. Minocycline administered before injury or early after experimental TBI (within $30 \mathrm{~min}$ ) has been shown to reduce neuronal death in focal open and closed head injury models $[5,35]$. In our model of TBI, the CA3 region of the hippocampus has been shown to be highly susceptible to neuronal death [1]. We utilized stereological quantification of this region as our initial metric as minocycline has not shown to be effective at altering neurogenesis or reducing white matter injury at acute time points [19, 29]. The highest dosing regimen $(180 \mathrm{mg} / \mathrm{kg}$ once a day) resulted in increased mortality compared with vehicle-injured mice. Mice receiving this higher dose of minocycline exhibited poor weight gain and acute impairments in gait and balance. Vestibular disturbances have been a reported side effect of minocycline use in humans and may account for the poor outcomes at this higher dose in our model [51]. We observed a dose-response in regards to neuroprotection in the CA3 region of the hippocampus with lower dosing ( $45 \mathrm{mg} / \mathrm{kg} /$ day) having no impact on neuroprotection and a robust response with dosing regimens of $90-135 \mathrm{mg} / \mathrm{kg} /$ day.

Minocycline has been shown to reduce microglial activation after CNS injury $[7,19]$. We did not detect differences in microglia cells numbers utilizing traditional stereological quantification approaches with either Iba1 or CD68 immunohistochemistry in the ipsilateral hippocampus 1 week post-injury. In contrast, a flow cytometry approach of the ipsilateral hippocampus and cortex revealed minocycline's anti-inflammatory properties with reduced number of microglia expressing MHCII. These differences found with orthogonal approaches could be attributed to stereological analysis being limited to the hippocampus and flow cytometry encompassing the entire injured cortex and hippocampus. We did not further explore changes in microglia phenotype populations in our studies. Future investigations utilizing advance techniques such as single cell RNA sequencing of microglia to further characterize minocycline induced changes in pro-inflammatory and anti-inflammatory microglia are planned.

Microglia, as the resident immune cells of the brain, are in part responsible for recruitment of peripheral immune cells to the site of injury $[2,4,28]$. Minocycline-treated mice had reduced $\mathrm{T}$ cell and monocyte infiltration into the hippocampus without any changes in peripheral blood immune cell numbers supporting the hypothesis that minocycline induced changes in the neuroinflammatory response are in large part due to reduced activation of microglia and subsequent reduced recruitment of peripheral immune cells to the brain. The role of the adaptive immune response in modulating the neuroinflammatory and thereby TBI severity and recovery remains unclear. $\mathrm{Rag}^{-1-}$ mice (absence of B and T cells) did not show any alteration in injury severity following CCI when evaluated 1 week after injury compared with wild type mice [50]. However, recent evidence has uncovered that the infiltration of lymphocytes peaks beyond the first week after TBI and subsets of T cells may have an impact on chronic neurodegeneration [13]. 
Timing and duration of minocycline administration in TBI may be a critical factor responsible for conflicting evidence for its neuroprotective efficacy in TBI. Seven days of minocycline administration after 3 repetitive head injuries in an immature rat model did reduce microglia activation but exacerbated cognitive deficits [19]. In a clinical trial of minocycline during the chronic phase of TBI demonstrated reduced microglial activation but elevations in plasma neurofilament light chain levels suggesting a detrimental effect of microglial activation on neurodegeneration in the chronic phase of TBI [39]. Pharmacologic depletion of microglia with PLX5622, CSF1R inhibitor, in a mouse model of TBI has demonstrated that the timing in relation to injury of microglial activation and repopulation has an impact on CNS pathology and recovery [52]. Our own findings of the protective/reparative effect of an acute short-term course of minocycline further highlight the temporal dependence of microglial manipulation's influence on injury severity and recovery in TBI.

Minocycline administration at lower doses in hypoxicischemic (HI) models of brain injury have been shown to reduce HI-induced oligodendrocyte cell death and myelin loss [7]. However in a closed head injury model, acute administration of minocycline immediately after injury for 3 or 10 days did not reduce white matter injury as measured by $\beta$-amyloid precursor protein immunohistochemistry [20]. Microglia depletion prior to close head injury attenuated transcriptional changes in OPCs and myelinating oligodendrocytes after injury implicating an important role for microglia in white matter injury and recovery [53]. Our own studies did not find increased survival in OPCs with minocycline at 1 week post injury but we did observe changes in OPC morphology in minocycline-treated mice. These data were associated with long-term (6 months) reduction in myelin loss in minocycline-treated mice. One possible explanation for our findings is that OPC morphological changes in minocycline-treated mice at 1 week post-injury are associated with increased maturation of OPCs to become myelin generating mature oligodendrocytes resulting in remyelination of demyelinated axons. Future studies assessing the impact of minocycline on mature oligodendrocytes after injury as well as studies utilizing primary OPC and activated microglia co-cultured with minocycline to better understand the impact of these morphologic changes on proliferation, maturation and function are planned.

There are limitations in the experimental approach when translating our findings to the clinical setting. We utilized young adult mice of both sexes in our longterm survival studies, but did not explore the impact of age, which may have impact on the neuroprotective effects of minocycline. We utilized an open focal model of head injury which has the advantage of being reproducible reducing variation and animal's number needed but does not encompass the full scope of TBI pathologies in the clinical setting. Our animal platform of TBI and delayed hypoxemia is modeled after the clinical scenario encountered by severe TBI patients in the intensive care setting [31]. All animals in our studies are required to return to general husbandry care limiting the severity of the TBI. We did not include an injury group without hypoxemia which limits our ability to untangle the effect of timing of minocycline administration in our model. Minocycline's neuroprotective properties could simply related to a longer temporal window of efficacy than previously reported or it could be acting as a "pre-treatment" to reduce the deleterious impact of delayed hypoxemia. We administered our study drug i.p., whereas it would be expected to be given intravenously in the ICU setting reducing the translatability of the dosing regimens we employed. Furthermore, we did not perform pharmacokinetic studies determining minocycline brain concentrations in our injured mice.

Together, our data demonstrate that in a clinically relevant rodent model of TBI with secondary insult, acute minocycline administration modulates the neuroinflammatory response resulting in short- and long-term neuroprotection and improved fear memory performance at a long-term time point rarely assessed in preclinical models of TBI. Timing in relation to injury and duration of minocycline treatment and its impact on neuroinflammatory response may be responsible for extensive neuroprotection observed in our studies. Future investigations utilizing similar timing and dosing of minocycline in alternative experimental TBI models and species should be performed to confirm the efficacy of minocycline prior to conducting clinical investigations.

\section{Supplementary Information}

The online version contains supplementary material available at https://doi. org/10.1186/s40478-022-01310-1.

Additional file 1: Figure S1. No immune system changes in the blood associated with acute minocycline administration after traumatic brain injury and delayed hypoxemia. a-d Peripheral immune system cell profile characterization by flow cytometry at 1 week after injury. Quantification of the absolute number of cells in the blood for a myeloid and lymphoid cells (CD45+), b CD3 Tcells (CD11b-CD3+), c monocytes (CD45highCD11b+Ly6C+), d neutrophils (CD45highCD11b+Ly6G+).

Additional file 2: Figure S2. Long-term behavior supplemental data. a Total distance and $b$ total time in center divided by sex. c Total time spent with objects, Kruskal-Wallis test. $p=0.01 .{ }^{*} p<0.05,{ }^{* *} p<0.01$. $d$ Discrimination index by sex. Fear conditioning e conditioning or day 1 , $\mathrm{f}$ contextual fear or day 2 two-way ANOVA followed by post hoc tukey test. Group $F(2,65)=59.44, p<0.0001, \operatorname{Sex} F(1,65)=6.684, p=0.12$, Sex ${ }^{*}$ Group interaction $F(2,65)=2.79, p=0.069 .{ }^{*} p<0.05$, g cued fear or day 3 


\section{Acknowledgements}

This work was supported by the National Institutes of Health (R01NS097721). Fluorescent imaging was performed on a Zeiss Axio Imager Z2 Fluorescence Microscope with ApoTome 2 optical sectioning grid imager through the use of Washington University Center for Cellular Imaging (WUCCI) supported by Washington University School of Medicine, The Children's Discovery Institute of Washington University and St. Louis Children's Hospital (CDI-CORE-2015-505 and CDI-CORE-2019-813) and the Foundation for Barnes-Jewish Hospital (3770 and 4642). Confocal imaging was generated on a Zeiss LSM 880 Airyscan Confocal Microscope which was purchased with support from the Office of Research Infrastructure Programs (ORIP), a part of the NIH Office of the Director under grant OD021629.

\section{Authors' contributions}

Conceptualization, M.C. and S.H.F.; Methodology, M.C., K.S, and S.H.F.; Investigation, M.C., K.S., C.P. S.V, and S.H.F.; Writing -Original Draft, M.C., K.S., C.P., and S.H.F.; Writing -Review \& Editing, M.C, K.S., C.P., and S.H.F.; Funding Acquisition, S.H.F.; Supervision, M.C., K.S., and S.H.F. All authors read and approved the final manuscript.

\section{Availability of data and material}

The datasets used and/or analyzed during the current study are available from the corresponding author on reasonable request.

\section{Declarations}

\section{Ethics approval}

All procedures were approved by the Washington University Animal Studies Committee (Protocol 19-0864) and are consistent with the National Institutes of Health guidelines for the care and use of animals.

\section{Consent for publication}

All authors have seen and approved the manuscript and have adhered to the standards of the National Research Council's Guide for the care and use of laboratory animals and the ARRIVE guidelines.

\section{Competing interests}

The authors have no competing interests, and the content of this manuscript has not been published, or submitted for publication elsewhere.

Received: 20 October 2021 Accepted: 8 January 2022

Published online: 28 January 2022

\section{References}

1. Anderson KJ, Miller KM, Fugaccia I, Scheff SW (2005) Regional distribution of Fluoro-Jade B staining in the hippocampus following traumatic brain injury. Exp Neurol 193:125-130. https://doi.org/10.1016/j.expneurol.2004. 11.025

2. Ankeny DP, Popovich PG (2009) Mechanisms and implications of adaptive immune responses after traumatic spinal cord injury. Neuroscience 158:1112-1121. https://doi.org/10.1016/j.neuroscience.2008.07.001

3. Bae S, Sheth C, Legarreta M, McGlade E, Lyoo IK, Yurgelun-Todd DA (2020) Volume and shape analysis of the Hippocampus and amygdala in veterans with traumatic brain injury and posttraumatic stress disorder. Brain Imaging Behav 14:1850-1864. https://doi.org/10.1007/ s11682-019-00127-2

4. Becher B, Prat A, Antel JP (2000) Brain-immune connection: Immuneregulatory properties of CNS-resident cells. Glia 29:293-304

5. Bye N, Habgood MD, Callaway JK, Malakooti N, Potter A, Kossmann T, Morganti-Kossmann MC (2007) Transient neuroprotection by minocycline following traumatic brain injury is associated with attenuated microglial activation but no changes in cell apoptosis or neutrophil infiltration. Exp Neurol 204:220-233. https://doi.org/10.1016/j.expneurol. 2006.10.013

6. Carney N, Totten AM, O'Reilly C, Ullman JS, Hawryluk GW, Bell MJ, Bratton SL, Chesnut R, Harris OA, Kissoon N et al (2017) Guidelines for the management of severe traumatic brain injury, fourth edition. Neurosurgery 80:6-15. https://doi.org/10.1227/NEU.0000000000001432
7. Carty ML, Wixey JA, Colditz PB, Buller KM (2008) Post-insult minocycline treatment attenuates hypoxia-ischemia-induced neuroinflammation and white matter injury in the neonatal rat: a comparison of two different dose regimens. Int J Dev Neurosci 26:477-485. https://doi.org/10.1016/j. ijdevneu.2008.02.005

8. Celorrio M, Abellanas MA, Rhodes J, Goodwin V, Moritz J, Vadivelu S, Wang L, Rodgers R, Xiao S, Anabayan I et al (2021) Gut microbial dysbiosis after traumatic brain injury modulates the immune response and impairs neurogenesis. Acta Neuropathol Commun 9:40. https://doi.org/10.1186/ s40478-021-01137-2

9. Celorrio M, Rhodes J, Vadivelu S, Davies M, Friess SH (2021) N-acetylcysteine reduces brain injury after delayed hypoxemia following traumatic brain injury. Exp Neurol 335:1 13507. https://doi.org/10.1016/j. expneurol.2020.113507

10. Chakraborty S, Skolnick B, Narayan RK (2016) Neuroprotection trials in traumatic brain injury. Curr Neurol Neurosci Rep 16:29. https://doi.org/10. 1007/s11910-016-0625-x

11. Cherian L, Robertson CS, Goodman JC (1996) Secondary insults increase injury after controlled cortical impact in rats. J Neurotrauma 13:371-383. https://doi.org/10.1089/neu.1996.13.371

12. Cornell J, Salinas S, Huang HY, Zhou M (2022) Microglia regulation of synaptic plasticity and learning and memory. Neural Regen Res 17:705-716. https://doi.org/10.4103/1673-5374.322423

13. Daglas M, Draxler DF, Ho H, McCutcheon F, Galle A, Au AE, Larsson $P$, Gregory J, Alderuccio F, Sashindranath M et al (2019) Activated CD8(+) T cells cause long-term neurological impairment after traumatic brain injury in mice. Cell reports 29:1178-+. https://doi.org/10.1016/j.celrep. 2019.09.046

14. Davies M, Jacobs A, Brody DL, Friess SH (2018) Delayed hypoxemia after traumatic brain injury exacerbates long-term behavioral deficits. J Neurotrauma 35:790-801. https://doi.org/10.1089/neu.2017.5354

15. Duhaime AC (2007) Why are clinical trials in pediatric head injury so difficult? Pediatr Crit Care Med 8:71

16. Eakin K, Baratz-Goldstein R, Pick CG, Zindel O, Balaban CD, Hoffer ME, Lockwood M, Miller J, Hoffer BJ (2014) Efficacy of N-acetyl cysteine in traumatic brain injury. PLOS ONE 9:e90617. https://doi.org/10.1371/journ al.pone.0090617

17. Erny D, Hrabe de Angelis AL, Jaitin D, Wieghofer P, Staszewski O, David E, Keren-Shaul H, Mahlakoiv T, Jakobshagen K, Buch T et al (2015) Host microbiota constantly control maturation and function of microglia in the CNS. Nat Neurosci 18:965-977. https://doi.org/10.1038/nn.4030

18. Fattoretti P, Malatesta M, Cisterna B, Milanese C, Zancanaro C (2018) Modulatory effect of aerobic physical activity on synaptic ultrastructure in the old mouse hippocampus. Front Aging Neurosci 10:141. https://doi. org/10.3389/fnagi.2018.00141

19. Hanlon LA, Huh JW, Raghupathi R (2016) Minocycline transiently reduces microglia/macrophage activation but exacerbates cognitive deficits following repetitive traumatic brain injury in the neonatal rat. J Neuropathol Exp Neurol 75:214-226. https://doi.org/10.1093/jnen/nlv021

20. Hanlon LA, Raghupathi R, Huh JW (2017) Differential effects of minocycline on microglial activation and neurodegeneration following closed head injury in the neonate rat. Exp Neurol 290:1-14. https://doi.org/10. 1016/j.expneurol.2016.12.010

21. Harris PA, Taylor R, Thielke R, Payne J, Gonzalez N, Conde JG (2009) Research electronic data capture (REDCap) — a metadata-driven methodology and workflow process for providing translational research informatics support. J Biomed Inform 42:377-381. https://doi.org/10.1016/j.jbi. 2008.08.010

22. Hei M, Chen P, Wang S, Li X, Xu M, Zhu X, Wang Y, Duan J, Huang Y, Zhao $S$ (2019) Effects of chronic mild stress induced depression on synaptic plasticity in mouse hippocampus. Behav Brain Res 365:26-35. https://doi. org/10.1016/j.bbr.2019.02.044

23. Henry RJ, Ritzel RM, Barrett JP, Doran SJ, Jiao Y, Leach JB, Szeto GL, Wu J, Stoica BA, Faden Al et al (2020) Microglial depletion with CSF1R inhibitor during chronic phase of experimental traumatic brain injury reduces neurodegeneration and neurological deficits. J Neurosci 40:2960-2974. https://doi.org/10.1523/JNEUROSCI.2402-19.2020

24. Homsi S, Piaggio T, Croci N, Noble F, Plotkine M, Marchand-Leroux C, Jafarian-Tehrani M (2010) Blockade of acute microglial activation by minocycline promotes neuroprotection and reduces locomotor 
hyperactivity after closed head injury in mice: a twelve-week follow-up study. J Neurotrauma 27:911-921. https://doi.org/10.1089/neu.2009.1223

25. Hutchison JS, Ward RE, Lacroix J, Hebert PC, Barnes MA, Bohn DJ, Dirks PB, Doucette S, Fergusson D, Gottesman R et al (2008) Hypothermia therapy after traumatic brain injury in children. N Engl J Med 358:2447-2456. https://doi.org/10.1056/NEJMoa0706930

26. Kochanek PM, Tasker RC, Carney N, Totten AM, Adelson PD, Selden NR, Davis-O'Reilly C, Hart EL, Bell MJ, Bratton SL et al (2019) Guidelines for the management of pediatric severe traumatic brain injury, third edition: update of the brain trauma foundation guidelines, executive summary. Pediatr Crit Care Med 20:280-289. https://doi.org/10.1097/PCC.00000 00000001736

27. Leger M, Quiedeville A, Bouet V, Haelewyn B, Boulouard M, SchumannBard P, Freret T (2013) Object recognition test in mice. Nat Protoc 8:2531-2537. https://doi.org/10.1038/nprot.2013.155

28. Needham EJ, Helmy A, Zanier ER, Jones JL, Coles AJ, Menon DK (2019) The immunological response to traumatic brain injury. J Neuroimmunol 332:112-125. https://doi.org/10.1016/j.jneuroim.2019.04.005

29. Ng SY, Semple BD, Morganti-Kossmann MC, Bye N (2012) Attenuation of microglial activation with minocycline is not associated with changes in neurogenesis after focal traumatic brain injury in adult mice. J Neurotrauma 29:1410-1425. https://doi.org/10.1089/neu.2011.2188

30. Pandya JD, Readnower RD, Patel SP, Yonutas HM, Pauly JR, Goldstein GA, Rabchevsky AG, Sullivan PG (2014) N-acetylcysteine amide confers neuroprotection, improves bioenergetics and behavioral outcome following TBI. Exp Neurol 257:106-113. https://doi.org/10.1016/j.expneurol.2014.04. 020

31. Parikh U, Williams M, Jacobs A, Pineda JA, Brody DL, Friess SH (2016) Delayed hypoxemia following traumatic brain injury exacerbates white matter injury. J Neuropathol Exp Neurol 75:731-747. https://doi.org/10. 1093/jnen/nlw045

32. Pernici CD, Rowe RK, Doughty PT, Madadi M, Lifshitz J, Murray TA (2020) Longitudinal optical imaging technique to visualize progressive axonal damage after brain injury in mice reveals responses to different minocycline treatments. Sci Rep 10:7815. https://doi.org/10.1038/ s41598-020-64783-X

33. Reger ML, Poulos AM, Buen F, Giza CC, Hovda DA, Fanselow MS (2012) Concussive brain injury enhances fear learning and excitatory processes in the amygdala. Biol Psychiatry 71:335-343. https://doi.org/10.1016/j. biopsych.2011.11.007

34. Roozenbeek B, Maas Al, Menon DK (2013) Changing patterns in the epidemiology of traumatic brain injury. Nat Rev Neurol 9:231-236. https:// doi.org/10.1038/nrneurol.2013.22

35. Sanchez Mejia RO, Ona VO, Li M, Friedlander RM (2001) Minocycline reduces traumatic brain injury-mediated caspase-1 activation, tissue damage, and neurological dysfunction. Neurosurgery 48:1393-1399; discussion 1399-1401. https://doi.org/10.1097/00006123-200106000-00051

36. Sauerbeck AD, Gangolli M, Reitz SJ, Salyards MH, Kim SH, Hemingway C, Gratuze M, Makkapati T, Kerschensteiner M, Holtzman DM et al (2020) SEQUIN multiscale imaging of mammalian central synapses reveals loss of synaptic connectivity resulting from diffuse traumatic brain injury. Neuron 107(257-273):e255. https://doi.org/10.1016/j.neuron.2020.04.012

37. Scheff SW, Sparks DL, Price DA (1996) Quantitative assessment of synaptic density in the outer molecular layer of the hippocampal dentate gyrus in Alzheimer's disease. Dementia 7:226-232. https://doi.org/10.1159/00010 6884

38. Schumacher M, Denier C, Oudinet JP, Adams D, Guennoun R (2016) Progesterone neuroprotection: the background of clinical trial failure. J Steroid Biochem Mol Biol 160:53-66. https://doi.org/10.1016/j.jsbmb. 2015.11.010

39. Scott G, Zetterberg H, Jolly A, Cole JH, De Simoni S, Jenkins PO, Feeney C, Owen DR, Lingford-Hughes A, Howes O et al (2018) Minocycline reduces chronic microglial activation after brain trauma but increases neurodegeneration. Brain 141:459-471. https://doi.org/10.1093/brain/awx339

40. Sen T, Saha P, Gupta R, Foley LM, Jiang T, Abakumova OS, Hitchens TK, Sen N (2020) Aberrant ER stress induced neuronal-IFN beta elicits white matter injury due to microglial activation and T-cell infiltration after TBI. J Neurosci 40:424-446. https://doi.org/10.1523/Jneurosci.0718-19.2019

41. Sharma R, Al Jayoussi G, Tyrer HE, Gamble J, Hayward L, Guimaraes AF, Davies J, Waterhouse D, Cook DA, Myhill $\amalg$ J et al (2016) Minocycline as a re-purposed anti-Wolbachia macrofilaricide: superiority compared with doxycycline regimens in a murine infection model of human lymphatic filariasis. Sci Rep 6:23458. https://doi.org/10.1038/srep23458

42. Simon DW, Aneja RK, Alexander H, Bell MJ, Bayir H, Kochanek PM, Clark RSB (2018) Minocycline attenuates high mobility group box 1 translocation, microglial activation, and thalamic neurodegeneration after traumatic brain injury in post-natal day 17 rats. J Neurotrauma 35:130-138. https://doi.org/10.1089/neu.2017.5093

43. Siopi E, Cho AH, Homsi S, Croci N, Plotkine M, Marchand-Leroux C, Jafarian-Tehrani M (2011) Minocycline restores sAPPalpha levels and reduces the late histopathological consequences of traumatic brain injury in mice. J Neurotrauma 28:2135-2143. https://doi.org/10.1089/neu. 2010.1738

44. Skolnick BE, Maas Al, Narayan RK, van der Hoop RG, MacAllister T, Ward JD, Nelson NR, Stocchetti N, Investigators ST (2014) A clinical trial of progesterone for severe traumatic brain injury. N Engl J Med 371:2467-2476. https://doi.org/10.1056/NEJMoa1411090

45. Strahan JA, Walker WH 2nd, Montgomery TR, Forger NG (2017) Minocycline causes widespread cell death and increases microglial labeling in the neonatal mouse brain. Dev Neurobiol 77:753-766. https://doi.org/10. 1002/dneu.22457

46. Strickland BA, Bakhsheshian J, Emmanuel B, Amar A, Giannotta SL, Russin $\mathrm{JJ}$, Mack W (2021) Neuroprotective effect of minocycline against acute brain injury in clinical practice: A systematic review. J Clin Neurosci 86:50-57. https://doi.org/10.1016/j.jocn.2021.01.005

47. Sullivan PG, Bruce-Keller AJ, Rabchevsky AG, Christakos S, Clair DK, Mattson MP, Scheff SW (1999) Exacerbation of damage and altered NF-kappaB activation in mice lacking tumor necrosis factor receptors after traumatic brain injury. J Neurosci 19:6248-6256

48. Thomale UW, Griebenow M, Kroppenstedt SN, Unterberg AW, Stover JF (2006) The effect of $\mathrm{N}$-acetylcysteine on posttraumatic changes after controlled cortical impact in rats. Intensive Care Med 32:149-155. https:// doi.org/10.1007/s00134-005-2845-4

49. Vonder Haar C, Anderson GD, Elmore BE, Moore LH, Wright AM, Kantor ED, Farin FM, Bammler TK, MacDonald JW, Hoane MR (2014) Comparison of the effect of minocycline and simvastatin on functional recovery and gene expression in a rat traumatic brain injury model. J Neurotrauma 31:961-975. https://doi.org/10.1089/neu.2013.3119

50. Weckbach S, Neher M, Losacco JT, Bolden AL, Kulik L, Flierl MA, Bell SE, Holers VM, Stahel PF (2012) Challenging the role of adaptive immunity in neurotrauma: Rag1 (-/ - ) mice lacking mature $B$ and $T$ cells do not show neuroprotection after closed head injury. J Neurotrauma 29:1233-1242. https://doi.org/10.1089/neu.2011.2169

51. Williams DN, Laughlin LW, Lee YH (1974) Minocycline: possible vestibular side-effects. Lancet 2:744-746. https://doi.org/10.1016/s0140-6736(74) 90941-6

52. Willis EF, MacDonald KPA, Nguyen QH, Garrido AL, Gillespie ER, Harley SBR, Bartlett PF, Schroder WA, Yates AG, Anthony DC et al (2020) Repopulating microglia promote brain repair in an IL-6-dependent manner. Cell 180(833-846):e816. https://doi.org/10.1016/j.cell.2020.02.013

53. Witcher KG, Bray CE, Chunchai T, Zhao F, O'Neil SM, Gordillo AJ, Campbell WA, McKim DB, Liu X, Dziabis JE et al (2021) Traumatic brain injury causes chronic cortical inflammation and neuronal dysfunction mediated by microglia. J Neurosci 41:1597-1616. https://doi.org/10.1523/JNEUROSCI. 2469-20.2020

54. Wright DW, Yeatts $S D$, Silbergleit $R$, Palesch $Y Y$, Hertzberg VS, Frankel $M$, Goldstein FC, Caveney AF, Howlett-Smith H, Bengelink EM et al (2014) Very early administration of progesterone for acute traumatic brain injury. N Engl J Med 371:2457-2466. https://doi.org/10.1056/NEJMoa1404304

\section{Publisher's Note}

Springer Nature remains neutral with regard to jurisdictional claims in published maps and institutional affiliations. 